\title{
Jacques Misan-Montefiore, L'Eau, le Rêve et le temps. Venise vue par les voyageurs français de 1850 à 1920
}

\section{Michel Arrous}

\section{(2) OpenEdition}

1 Journals

\section{Édition électronique}

URL : https://journals.openedition.org/studifrancesi/45935

DOI : $10.4000 /$ studifrancesi.45935

ISSN : 2427-5856

Éditeur

Rosenberg \& Sellier

\section{Édition imprimée}

Date de publication : 1 octobre 2007

Pagination : 452

ISSN : 0039-2944

\section{Référence électronique}

Michel Arrous, « Jacques Misan-Montefiore, L'Eau, le Rêve et le temps. Venise vue par les voyageurs

français de 1850 à 1920 », Studi Francesi [En ligne], 152 (LI | II) | 2007, mis en ligne le 30 novembre 2015, consulté le 24 novembre 2021. URL : http://journals.openedition.org/studifrancesi/45935; DOI : https://doi.org/10.4000/studifrancesi.45935

Ce document a été généré automatiquement le 24 novembre 2021.

\section{(c) 9 (i) $\Theta$}

Studi Francesi è distribuita con Licenza Creative Commons Attribuzione - Non commerciale - Non opere derivate 4.0 Internazionale. 


\title{
Jacques Misan-Montefiore, L'Eau, le Rêve et le temps. Venise vue par les voyageurs français de 1850 à 1920
}

\author{
Michel Arrous
}

\section{RÉFÉRENCE}

JACQUES MISAN-MONTEFIORE, L'Eau, le Rêve et le temps. Venise vue par les voyageurs français de 1850 à 1920, Moncalieri, Centro Interuniversitario di Ricerche sul «Viaggio in Italia», 2003, pp. 246.

1 Après la Venise des voyageurs romantiques français (Moncalieri, C.I.R.V.I., 2000), Jacques Misan-Montefiore a poursuivi son enquête jusqu'en 1920. La Venise des naturalistes et des décadents, surtout de ces derniers qui y trouveront leur patrie d'lection, est évoquée dans sept chapitres bien documentés consacrés aux principaux aspects du mythe: la mer, l'eau et les îles, le charme, la femme et l'amour, etc. Barrès (La Mort de Venise, 1902), d'Annunzio (Il Fuoco, 1907), Suarès (Voyage du condottière. Vers Venise, 1914) exerceront une puissante emprise sur les voyageurs et les romanciers fascinés. Leur vision et leur interprétation sont en quelque sorte confirmées par de nombreux écrivains sauvés d'un profond oubli grâce à des citations nombreuses et bien venues. Si le Voyage du condottière trouve heureusement des lecteurs, qui lit aujourd'hui Le Mystère vénitien de Ferdinand Bac (1909) ou Sous le Ciel vénitien de Robert Hénard (1911) - qui sont sans doute bien plus que des itinéraires descriptifs -, voire les voyages d'Arsène Houssaye ou de Xavier Marmier, ou celui du très stendhalien Gabriel Faure? Il en va de même pour tel roman d'Abel Hermant ou pour les pages qu'Henri de Régnier a consacrées à Venise, de 1910 à 1930. Au gré des citations, on se prend parfois à regretter cet oubli.

2 Tous chantent la "ville au rêve éveillé», le charme de ses eaux et de sa lumière, la fraîcheur de ses ombres et le pittoresque de ses rues; tous mettent leurs pas dans les 
pas de Chateaubriand, Musset ou Gautier, à la Piazzetta, à San Marco ou à la Cà d'Oro. Tous redécouvrent un sublime sensuel que résumé une belle déclaration de Suarès: «J'aime cette ville. Elle est mon désir». Cette jouissance érotique que procure la possession de Venise, l'exemple le plus fameux en est donné par d'Annunzio qui fait de Venise la ville de la femme et de l'amour; c'est aussi, pour Thomas Mann, ou pour Frederick Rolfe, alias le Baron Corvo, qui y cherche «the desire and pursuit of the whole», la ville de la passion homosexuelle. Venise c'est aussi et surtout la ville en proie à l'usure du temps à travers l'infinie variété des heures et des saisons, aspect abondamment illustré par Henri de Régnier et Anna de Noailles. Sans doute aurait-il fallu accorder plus d'attention à la «Venise intérieure» de Proust.

Si les romantiques ont souvent rappelé la gaïeté de la ville de Goldoni et de Casanova, les décadents ont préféré la Venise morbide, non sans une pointe de nostalgie pour la Venise de cet âge d'or que fut le Settecento. Même si le carnaval devient en ces années une opération mercantile, les décadents se laissent griser par sa théâtralité.

4 Le dernier chapitre - «Venise et la mort» - s'imposait. Mort de Venise, mort à Venise: le thème romantique s'amplifie jusqu'au délire. Une mort palpable et infinie que Barrès, Lorrain et leurs épigones vont mettre en scène sous le double sceau de la pourriture physique et morale qui séduit les dandys européens. Ville des eaux, de la nuit et du silence, ville de la lassitude gagnée par la mort, cette «ruine romantique» fut aussi et paradoxalement la ville de l'union indissoluble de la vie et de la mort, avant de «chavirer sous le poids des imbéciles». Au voyageur ou à l'écrivain décadent succédera, dès l'après-guerre, le touriste, autrement dit «l'idiot de Venise», selon la formule vengeresse de Régis Debray (Contre Venise, 1995), qui pratiquera autrement le voyage passionné. Fin d'un mythe? Des notes abondantes et une riche bibliographie font de ce volume un complément nécessaire à l'Antologie des voyageurs français aux XVIII et au XIX siècles d'Yves Hersant (Robert Laffont, 1988). À l'enquête de J. Misan-Montefiore sur les représentations littéraires de Venise à l'époque romantique et décadente, Christian Del Vento et Xavier Tabet viennent de donner un utile complément avec Le Mythe de Venise au XIXe siècle. Débats historiographiques et représentations littéraires (Presses Universitaires de Caen, 2006, p. 256). 